\title{
Simulation of Temperature and Precipitation Climatology for Georgia using RegCM4
}

\author{
Mariam Elizbarashvili $^{1}$, Magda Tsintsadze ${ }^{1}$, Tsezari Mshvenieradze ${ }^{1}$ \\ ${ }^{1}$ Ivane Javakhishvili Tbilisi State University \\ Ilia Tchavtchavadze Avenue 1, \\ Academic Building I, 0179 Tbilisi, Georgia \\ Mariam.elizbarashvili@tsu.ge; magda.tsintsadze@tsu.ge \\ tsezarimshvenieradze@gmail.com
}

\section{Extended Abstract}

Georgia is a small mountainous country. It is situated in the Eastern part of the South Caucasus. Mountains cover a significant part of the territory with $54 \%$ being located at an altitude of $1,000 \mathrm{~m}$ above sea level or higher. To the west it borders with the Black Sea. Georgia is very sensitive to climate change as significant changes have already observed largely due to its complex topography and proximity to the sea $[1,2]$.

The performance of a regional climate model RegCM4.7.0 (RegCM4) in simulating the present-day climate of Georgia has been evaluated.

RegCM was originally developed at the National Centre for Atmospheric Research (NCAR, USA) and is currently maintained at the Abdus Salam International Centre for Theoretical Physics (ICTP) in Trieste, Italy. RegCM is a family of limited area models $[3,4]$, in which the large scale meteorological fields from AOGCM simulations provide initial and timedependent meteorological lateral boundary conditions (LBCs) for high resolution RegCM simulations. RegCM has been successfully applied to studies of regional climate and seasonal predictability around the world [5].

RegCM4.7.0 has been forced with the boundary conditions obtained from the global reanalysis dataset ERA-Interim for the period 1985-1990.

The domain was selected to be large enough to account for the relevant large-scale processes (such as the large-scale flow modulations due to orographic features and water bodies) but at the same time small enough in size to minimize the use of computational resources.

$20 \mathrm{~km}$ grid spacing simulated annual near surface air temperature and precipitation was compared with the gridded observation data sets of the Climatic Research Unit (CRU) and University of Delaware (UDEL). The model performed well in capturing the temperature and precipitation climatology for $20 \mathrm{~km}$ grid spacing for Georgia domain.

As a result of this study mean temperature and precipitation distribution maps were created for Georgia domain for the period 1985-1990.

Given the complex topography of Georgia and relatively very few climate modeling studies, the expected outcomes of the project are very important for the country from both societal and scientific points of view.

This work was supported by Shota Rustaveli National Science Foundation of Georgia (SRNSFG) № FR-19-8110.

\section{References}

[1] E. Sh. Elizbarashvili, M. R.Tatishvili, M. E. Elizbarashvili, Sh. E. Elizbarashvil, R. Sh. Meskhia, "Air temperature trends in Georgia under global warming conditions", Russian Meteorology and Hydrology, Vol. 38, Issue 4, pp. 234238, 2013

[2] I. Keggenhoff, M. Elizbarashvili, and L. King, "Recent changes in Georgia's temperature means and extremes: Annual and seasonal trends between 1961 and 2010", Weather and Climate Extremes, Vol. 8, pp. 34-45, 2015.

[3] Dickinson, R. E., A. Henderson-Sellers, and P. J. Kennedy, "Biosphere-atmosphere transfer scheme (BATS) version 1e as coupled to the NCAR community climate model", Tech. rep., National Center for Atmospheric Research,1993.

[4] Filippo Giorgi, Nellie Elguindi, Stefano Cozzini and Graziano Giuliani. Regional Climatic Model RegCM User's Guide Version 4.4, Trieste, Italy, 2013.

[5] Giorgi, F. "Simulation of regional climate using a limited area model nested in a general circulation model", J.Climate, vol.3, pp. 941-963,1990 